\title{
Effect of the Preheating Inlet Air on the G222 Fuel Combustion
}

\author{
Mohammed El Hadi Attia ${ }^{1}$, Zied Driss ${ }^{2}$ and Abderrahmane Khechekhouche ${ }^{3}$ \\ ${ }^{I}$ Department of Physics, Faculty of Science, University of El Oued, 39000 El Oued, ALGERIA \\ ${ }^{2}$ Laboratory of Electro-Mechanic Systems (LASEM), ENIS, University of Sfax, TUNISIA \\ ${ }^{3}$ Renewable Energy development unit in Arid Zones (UDERZA), University of El-Oued, ALGERIA
}

attiameh@gmail.com

\begin{abstract}
In this paper, a numerical simulation is developed to study the preheating effect of the air in a three-dimensional cylindrical combustion chamber using the FLUENT-CFD code. Particularly, we are interested on the calculation of the characteristic parameters such as the axial velocity, the temperature and the mass fraction of carbon monoxide. This study consists of a special treatment of mathematical models. The considered approaches resolve the governing equations of system. The main objective of this work is to study the behavior of the parameters considered previously during the variation of the air inlet temperature. The obtained results show that the variation of the inlet temperature presents a direct effect on the considered parameters.
\end{abstract}

Keywords: Premixed Combustion; Turbulence; Fuel G222; Preheating, Computational Fluid Dynamics.

Received: 02/09/2018 - Accepted: 25/11/2018

\section{Introduction}

Turbulent combustion is found in industry most often in gas burners, turbojets and rocket engines. Turbulence plays an essential role in mixing as quickly as possible the gases present. It is essentially due to the strong gradients of velocity that exist at the air entrance $[1,2]$. This fact is encountered in the industrial sector. As an example, we can found it in the burners used to convert the stored energy in the molecular bonds of fuels into thermal energy and then into mechanical energy. Thus, controlling combustion is a vital capacity in the development of new industrial systems, such as propulsion systems $[3,5]$. One of the challenges that industry must face today in order to accompany technological development is to reduce the impact of combustion on the environment. This impact is manifested in the release of polluting chemical species, of which oxides of nitrogen $\left(\mathrm{NO}_{\mathrm{x}}\right)$ and gases participating in the greenhouse effect, such as carbon oxides, $\mathrm{CO}$ and $\mathrm{CO}_{2}$. This challenge forces engine manufacturers to propose ever more innovative solutions to achieve the objectives set.

Several works aim to minimize these emissions by introducing techniques such as lean burning, combustion of fuels of renewable origin and which does not contain carbon.

Hydrogen $\mathrm{H}_{2}$ and methane $\mathrm{CH}_{4}$ are two important fuels from an energy point of view. $\mathrm{CH}_{4}$ has a significant practical application in the energy sector since it is the major constituent of natural gas. Hydrogen is a clean, carbon-free fuel. Its combustion produces only water and a reduced amount of nitrogen oxides. Indeed Hydrogen is not a primary energy but an energy vector [6]. The effect of preheating air in a combustion chamber provides significant energy savings and reduces fuel consumption, coupled with $\mathrm{CO}$ reduction techniques, and has found applications in several sectors Industrial sectors.

The main objective of this work is to present a $3 \mathrm{D}$ thermo chemistry study in a cylindrical combustion chamber fed by G222. In these conditions, the mixture named G222 is based on $77 \%$ of methane and $23 \%$ of hydrogen. Starting with injection of G222 and air at the same temperature equal to $\mathrm{T}=300 \mathrm{~K}$, the temperature of the fuel is then fixed to the previous value and the temperature inlet of the air is varied at $\mathrm{T}=300 \mathrm{~K}, \mathrm{~T}=500$ $\mathrm{K}, \mathrm{T}=750 \mathrm{~K}$ and $\mathrm{T}=900 \mathrm{~K}$. The simulation was carried out by the CFD code FLUENT. The obtained results show that the preheating of the air presents a direct impact on the parameters of the combustion.

\section{Mathematical Formulation of the Problem}

The equilibrium equations of the aero-thermochemistry used for the combustion study with a compressible flow [5-8] are defined by the continuity equation:

$\frac{\partial \bar{\rho}}{\partial t}+\frac{\partial}{\partial x_{i}}\left(\bar{\rho} \tilde{u}_{i}\right)=0$

The momentum equations are written as follows: 


$$
\frac{\partial \bar{\rho} \tilde{u}_{i}}{\partial t}+\frac{\partial}{\partial x_{i}}\left(\bar{\rho} \tilde{u}_{i} \widetilde{u}_{j}\right)=-\frac{\partial}{\partial x_{i}}\left[\bar{\rho}\left(\overline{u_{i} u_{j}}-\tilde{u}_{i} \widetilde{u}_{j}\right)\right]-\frac{\partial \bar{p}}{\partial x_{j}}+\frac{\partial \overline{\tau_{i j}}}{\partial x_{i}}
$$

The energy equation is written as follows:

$\frac{\partial}{\partial t} \bar{\rho} \tilde{h}+\frac{\partial}{\partial x_{i}}\left(\bar{\rho} \tilde{u}_{i} \tilde{h}\right)=-\frac{\partial}{\partial x_{i}}\left[\bar{\rho}\left(\overline{u_{i} h}-\tilde{u}_{i} \tilde{h}\right)\right]+\frac{\partial \bar{p}}{\partial t}+\frac{\partial}{\partial x_{i}} \overline{u_{j} \tau_{i j}}$

The species equations are written as follows:

$\frac{\partial}{\partial t} \bar{\rho} \widetilde{Y}_{f}+\frac{\partial}{\partial x_{i}}\left(\bar{\rho} u_{i} \widetilde{Y}_{f}\right)=-\frac{\partial}{\partial x_{i}}\left[\bar{\rho}\left(\overline{u_{i} Y_{f}}-\widetilde{u}_{i} \widetilde{Y}_{f}\right)\right]+\overline{\dot{\omega}}_{f}$

Where $\mathrm{i}=1,2,3$ and $\mathrm{j}=1,2,3$.

The thermodynamic state is written as follow:

$$
\bar{p}=\bar{\rho} R_{m} \tilde{T}
$$

In these equations, the unresolved Reynolds stresses $\left(\overline{u_{i} u_{j}}-\tilde{u}_{i} \tilde{u}_{j}\right)$ require a subgrid scale turbulence model. The unresolved species fluxes $\left(\overline{u_{i} Y_{f}}-\widetilde{u}_{i} \widetilde{Y}_{f}\right)$ and the enthalpy fluxes $\left(\overline{u_{i} h}-\widetilde{u}_{i} \tilde{h}\right)$ require a probability density function (PDF) approach. The filtered chemical reaction rate is characterized by $\overline{\dot{\omega}}_{f}$.

The LES models and the PDF approach are explained and detailed in our previous work [5-8].

\section{Experimental Configuration}

As presented in figure 1, the considered combustion chamber shows a cylindrical shape with a radius $\mathrm{R} 4=61$ $\mathrm{mm}$ and a length $\mathrm{L}=1 \mathrm{~m}$ fed by two coaxial jets. The central jet has an internal radius $\mathrm{R} 1=31.57 \mathrm{~mm}$ and an external radius $\mathrm{R} 2=31.75 \mathrm{~mm}$, to inject the fuel $\mathrm{G} 222$ with a mass flow $\mathrm{Q} 1=7.2 \mathrm{~g} / \mathrm{s}$ at a temperature $\mathrm{T} 1=300 \mathrm{~K}$. The annular jet presents an internal ray $\mathrm{R} 3=46 \mathrm{~mm}$, injecting a preheated air a mass flow rate $\mathrm{Q} 2=137 \mathrm{~g} / \mathrm{s}$ at different temperatures equal to $\mathrm{T}=300 \mathrm{~K}, \mathrm{~T}=500 \mathrm{~K}$, $\mathrm{T}=750 \mathrm{~K}$ and $\mathrm{T}=900 \mathrm{~K}$. The combustion chamber is pressurized at $3.8 \mathrm{~atm}$ with a isothermal temperature equal to $\mathrm{T}=500 \mathrm{~K}$ [9-14]. Moreover, the presentation and comparison of results are based on normalizing length and velocity by using, respectively, the injector radius $\mathrm{R} \equiv \mathrm{R} 3$ and the inlet bulk velocity of the air $\mathrm{U} \equiv \mathrm{V} 2$.

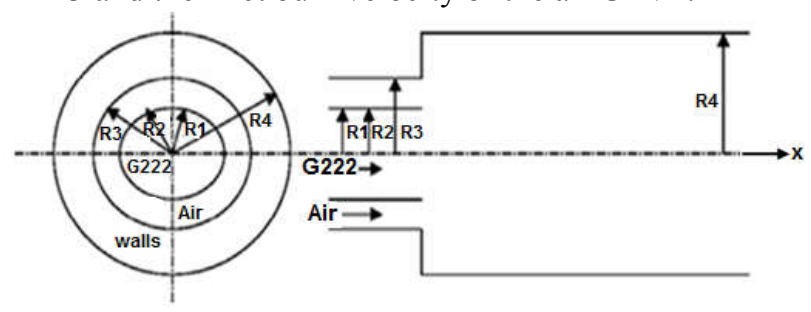

Figure 1. Geometrical arrangement of the combustion chamber.

\section{Results and Discussions}

The equations of the balance sheet are solved by the finite volume method. The mesh used is of the hybrid type so that prisms are chosen at the centers and parallelepipeds in the rest of the field of study of the combustion chamber.

\section{IV.1. Axial velocity}

Figure 2 illustrates the radial profiles of the average axial velocity obtained by numerical calculation. According to these results, it has been observed that the high velocity values are located in the area of the flame presented by the peak in both stations defined by $\mathrm{x} / \mathrm{R}=0.14$ and 0.38 . Indeed, these profiles show the same pattern when the production of the mixture layer presented by the peak is located approximately in the same position. The curves represent some change in the average velocity in the nonpremixed cylindrical combustion chamber when the radial distance changes from $\mathrm{x} / \mathrm{R}=0.14$ to $\mathrm{x} / \mathrm{R}=0.38$. Indeed, it has been noted that the different profiles are superimposed identically with a slight decrease of the average velocity which is affected by the preheating of the air. In these conditions, the maximum value of the axial velocity is equal to $\mathrm{V}=23 \mathrm{~m} \cdot \mathrm{s}^{-1}$ for $\mathrm{T}=300 \mathrm{~K}$. However, it is equal to $\mathrm{V}=20 \mathrm{~m} \cdot \mathrm{s}^{-1}$ for $\mathrm{T}=750 \mathrm{~K}$.

Figure 3 shows a $2 \mathrm{D}$ view of the axial velocity distribution in the non-premixed cylindrical combustion chamber confined by two coaxial G222/air jets. In these cases, the iso-surfaces of the temperature are defined with the inlet conditions characterized by an air temperature equal to $\mathrm{T}=750 \mathrm{~K}$ and a G222 fuel temperature equal to $\mathrm{T}=300 \mathrm{~K}$. We consider that high values of velocity are located in the flame zone, however, the velocity decrease when we go far to this region.
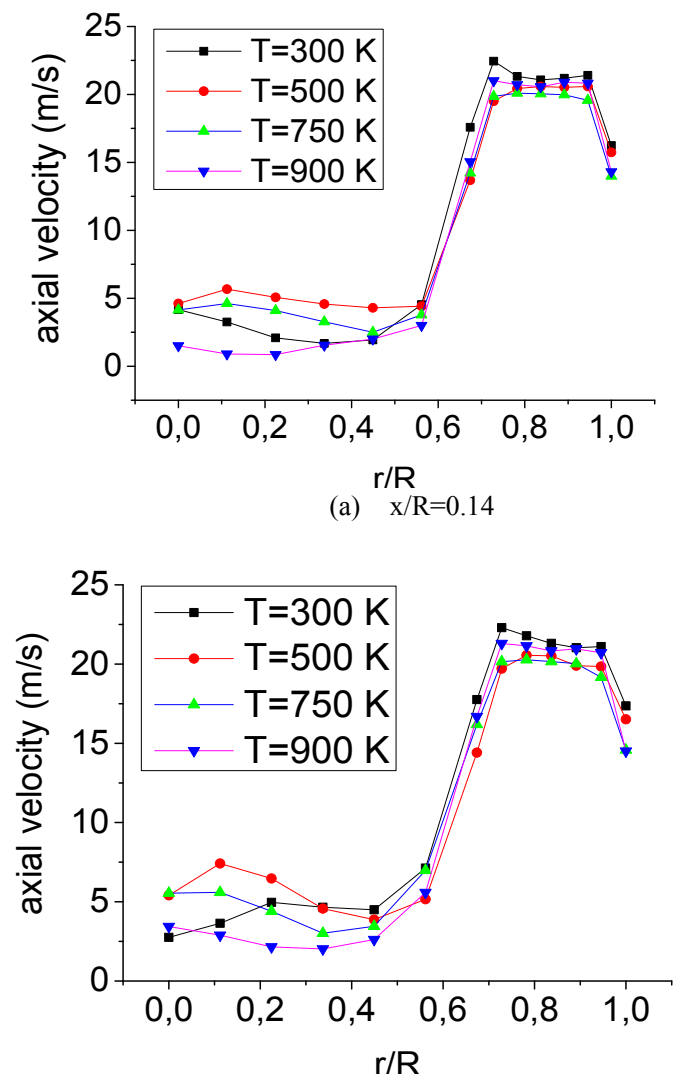

(b) $\mathrm{x} / \mathrm{R}=0.38$

Figure 2. Radial profiles of the axial velocity. 

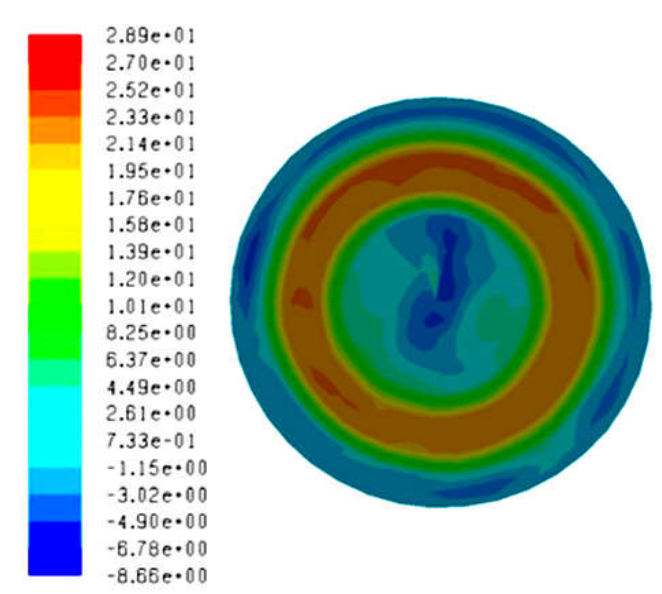

(a) $\mathrm{x} / \mathrm{R}=0.14$
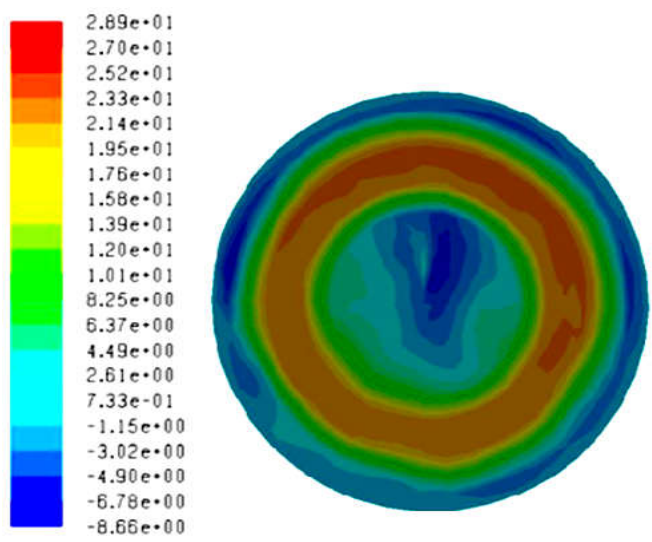

(b) $\mathrm{x} / \mathrm{R}=0.38$

Figure 3. Distribution of the axial velocity.

\section{IV.2. Temperature}

Figure 4 illustrates the temperature profiles in the combustion chamber during a non-premixed combustion of the G222. According to these results, these profiles present the same appearance. In these conditions, the highest value of the temperature appears in the vicinity of the flame areas and it is equal to $\mathrm{T}=2300 \mathrm{~K}$. However, it is very low near the burner wall, where the temperature is equal to $\mathrm{T}=500 \mathrm{~K}$. The area of the flame is a zone of chemical reaction of the fuel with air, so this source of heat is generated by the chemical reactions caused by the rupture of carbon bonds and hydrogen, Oxygen to produce $\mathrm{H}_{2} \mathrm{O}, \mathrm{CO}_{2}, \mathrm{CO}$ and $\mathrm{OH}$. The preheating zone defined by $\mathrm{T}=750 \mathrm{~K}$ is located at $\mathrm{x} / \mathrm{R}=0.14$. The peak value characterized by $\mathrm{T}=1950 \mathrm{~K}$ at the position $\mathrm{r} / \mathrm{R}=0.45$. However, at $\mathrm{x} / \mathrm{R}=0.38$ and $\mathrm{r} / \mathrm{R}=0.45$, the temperature is equal to $\mathrm{T}=2000 \mathrm{~K}$. Figure 5 shows a $2 \mathrm{D}$ view of the temperature distribution in the non-premixed cylindrical combustion chamber confined by two coaxial G222/air jets. These iso-surfaces of the temperature are defined with the inlet conditions characterized by an air temperature equal to $\mathrm{T}=750 \mathrm{~K}$ and a $\mathrm{G} 222$ fuel temperature equal to $\mathrm{T}=300 \mathrm{~K}$. the results show that the high temperature is produced by the combustion.
Whereas, high values of temperature are located near the flame region.

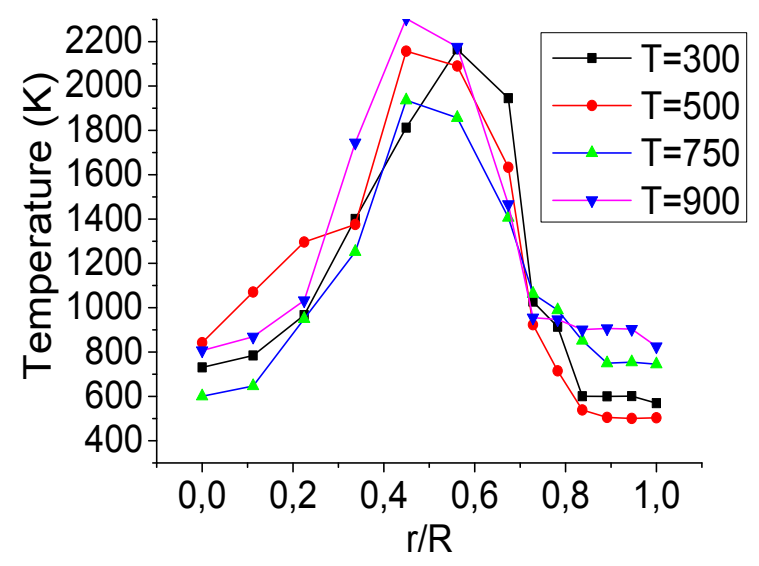

(a) $\mathrm{x} / \mathrm{R}=0.14$

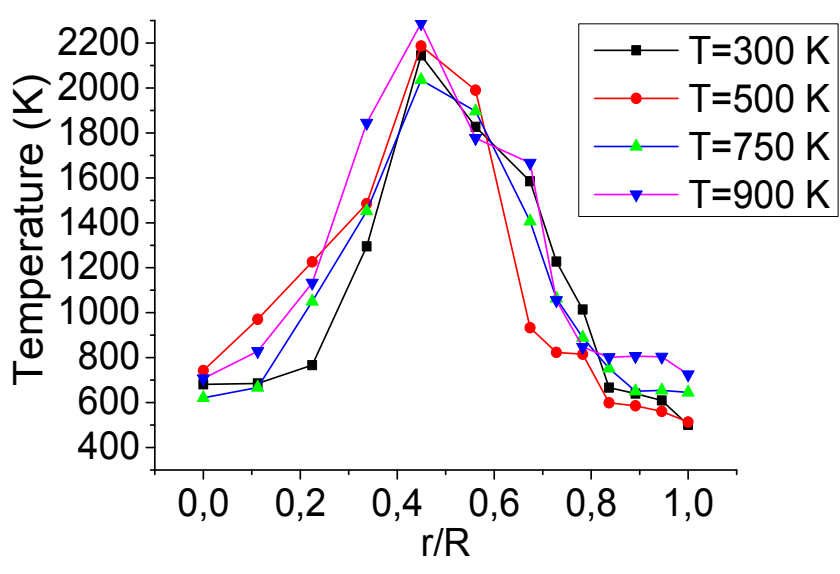

(b) $\mathrm{x} / \mathrm{R}=0.38$

Figure 4. Radial profiles of the temperature.

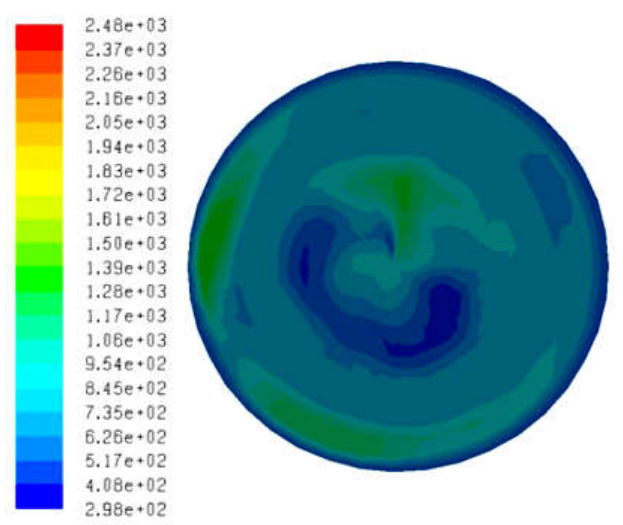

(a) $\mathrm{x} / \mathrm{R}=0.14$ 


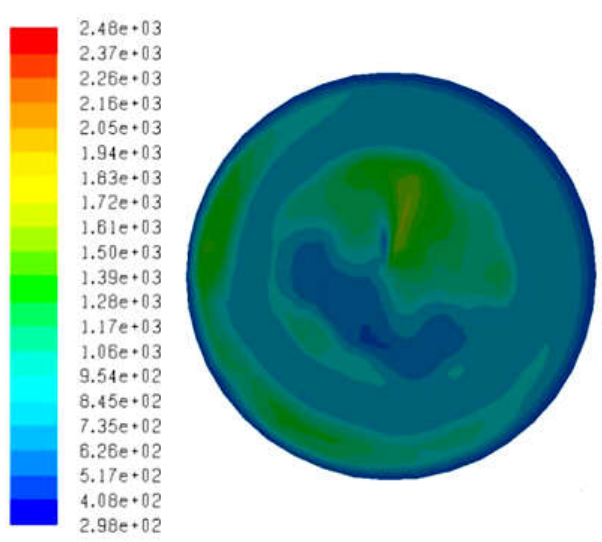

(b) $\mathrm{x} / \mathrm{R}=0.38$

Figure 5. Distribution of the temperature.

\section{IV.3. CO Fraction Mass}

Figure 6 presents the mass fraction of the carbon monoxide $\mathrm{CO}$ produced during the combustion of the fuel G222. According to these results, it has been noted that the mass fraction of the $\mathrm{CO}$ presents high values in the middle of the combustion chamber and decreases until reaching the zero value in the vicinity of the walls of the combustion chamber. Indeed, it has been observed that the mass fraction of the $\mathrm{CO}$ decreases when moving away from the inlet of the combustion chamber near the flame area. This fact can be explained by the secondary reaction of the $\mathrm{CO}$ with $\mathrm{O}_{2}$ to become $\mathrm{CO}_{2}$. These results present the same distribution founded for the temperature. This fact means that the region of the flame is rich in $\mathrm{CO}$, produced by the combustion. The comparison between these curves confirms that the choice of the air inlet temperature equal to $\mathrm{T}=750 \mathrm{~K}$ can improve the $\mathrm{CO}$ reduction. In these conditions, the $\mathrm{CO}$ mass fraction is equal to $\mathrm{M}_{\mathrm{CO}}=0.07$ at the position defined by $x / R=0.14$ and $r / R=0.35$. However, it is equal to $\mathrm{M}_{\mathrm{CO}}=0.05$ at the position defined by $\mathrm{x} / \mathrm{R}=0.38$ and $\mathrm{r} / \mathrm{R}=0.55$.

Figure 7 shows a 2D view of the distribution of the carbon monoxide $\mathrm{CO}$ mass fraction in the non-premixed cylindrical combustion chamber confined by two G222/air coaxial jets. These iso-surfaces correspond to the inlet conditions characterized by an air temperature $\mathrm{T}=750 \mathrm{~K}$ and a $\mathrm{G} 222$ fuel temperature equal to $\mathrm{T}=300 \mathrm{~K}$. According to these results, it has been observed that the maximum value of the $\mathrm{CO}$ mass fraction appears near the axis. Elsewhere, it presents a very weak value, particularly near the lateral surface. We observe that the $\mathrm{CO}$ profiles have same tendency with the temperature. Because the $\mathrm{CO}$ is produced by the combustion of $\mathrm{CH}_{4}$ found in G222.

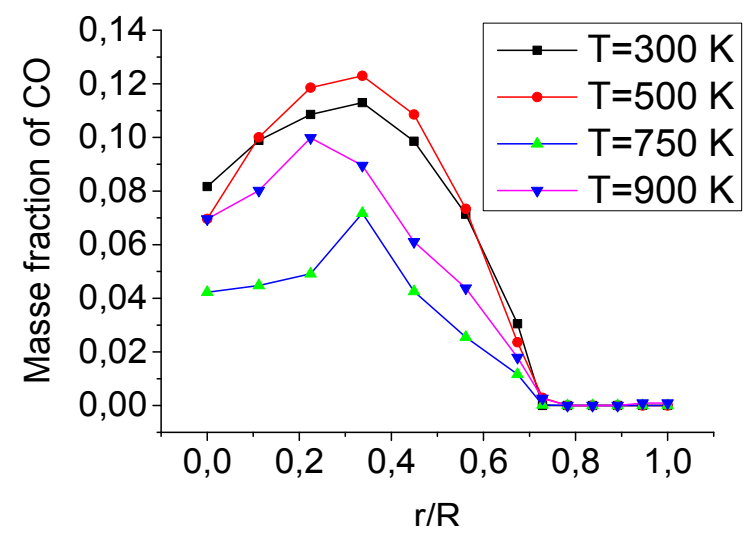

(a) $\mathrm{x} / \mathrm{R}=0.14$

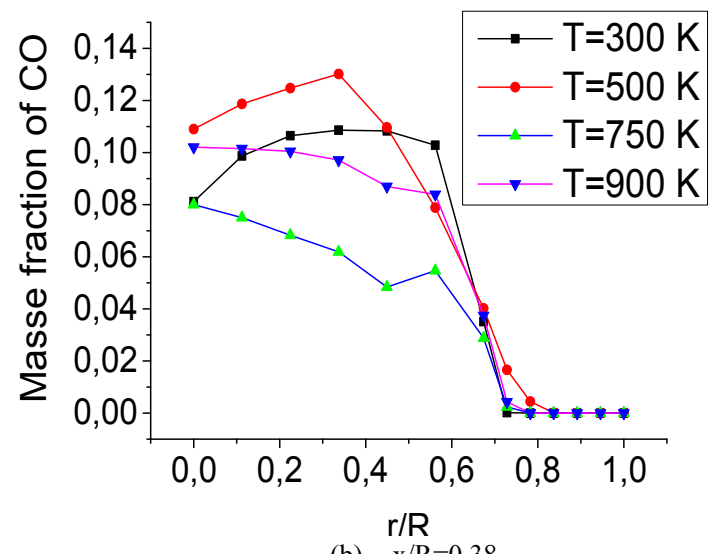

(b) $\mathrm{x} / \mathrm{R}=0.38$

Figure 6. Radial profiles of the $\mathrm{CO}$ mass fraction.
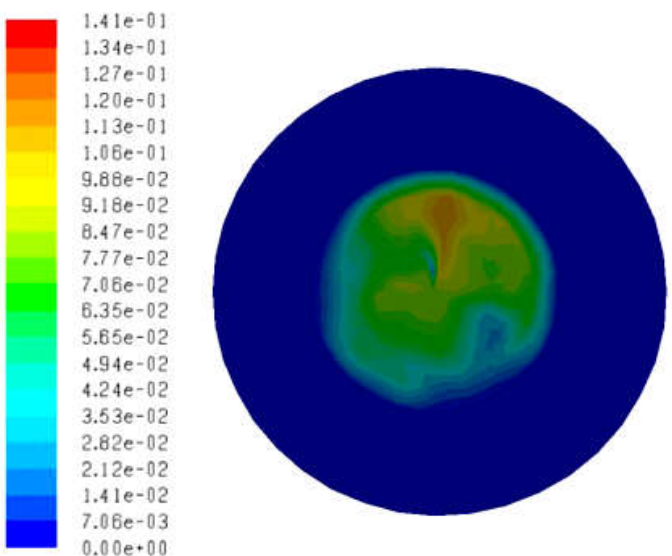

(a) $\mathrm{x} / \mathrm{R}=0.14$ 

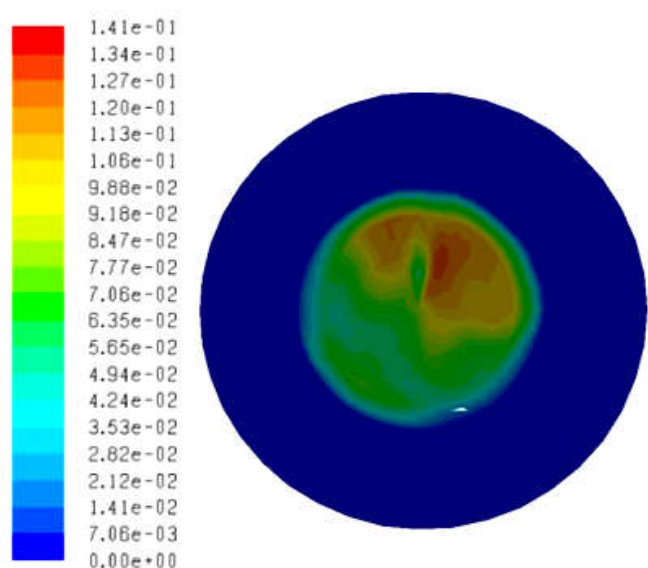

(b) $\mathrm{x} / \mathrm{R}=0.38$

Figure 7. Distribution of the CO mass fraction.

\section{Conclusions}

This paper presents a numerical simulation to model the preheating effect in a non-premixed combustion powered by the fuel G222. In this work, the phenomenon of the injected air preheating is considered with injection of the fuel $\mathrm{G} 222$ at a constant temperature equal to $\mathrm{T}=300 \mathrm{~K}$ and for different air inlet temperature equal to $\mathrm{T}=300 \mathrm{~K}$, $\mathrm{T}=500 \mathrm{~K}, \mathrm{~T}=750 \mathrm{~K}$ and $\mathrm{T}=900 \mathrm{~K}$.

The obtained results allow us to the following remarks:

- The ideal and suitable air temperature which gives a good and comfortable compromise to drive combustion studied and less loss of energy is equal to $\mathrm{T}=750 \mathrm{~K}$. Also, we confirm that the temperature of the fuel is equal to $\mathrm{T}=300 \mathrm{~K}$.

- The carbon monoxide $\mathrm{CO}$ emissions are reduced in the case of the intake conditions characterized by the air temperature equal to $\mathrm{T}=750 \mathrm{~K}$ and the fuel temperature equal to $\mathrm{T}=300 \mathrm{~K}$.

\section{References}

[1] F. Bouras, A. Soudani and M. Si-Ameur, Simulation aux grands échelles de la combustion turbulente couplée à des fonctions densités de probabilité, Proceeding of International Conference on Energetics and Pollution, 2007, pp. 45-50.

[2] F. Tabet, B. Sarhb and I. Gokalp, Hydrogen-hydrocarbon turbulent non-premixed flame structure, International journal of hydrogen energy, vol.34, 2009, pp. 5040-5047.

[3] B. X. Liu, P. Sun, H. Q. Ning, J. Meng, H. Huang, "Simulation of Heat Transfer by Fluid Structure Interaction of Diesel Engine Block - Coolant Jacket", Journal of Mechanical Engineering Research and Developments, vol. 38, no. 2, 2015, pp. 36-42.

[4] F. Bouras, A.Soudani, and M. Si Ameur, Thermochemistry Study of Internal Combustion Engine, Energy Procedia, vol.18, 2012, pp. 1086-1095.

[5] F. Bouras, A. Soudani, and M. Si Ameur, Beta-PDF Approach for Large Eddy Simulation of Non-premixed Turbulent Combustion, International Review of Mechanics Engineering, vol. 4, 2010, pp. 1096-1099.
[6] C. P. Pierce, P. Moin, Progress-Variable Approach for Large-Eddy Simulation of Non-Premixed Turbulent Combustion, Journal of Fluid Mechanics, vol. 504, 2004, pp 73-97.

[7] J. H. Tang, Y. Y. Zuo, S. Y. Bei, \& K. Y. Wang, Numerical Calculation and Analysis of Automobile Aerodynamic Noise Based on Large Eddy Simulation, Journal of Mechanical Engineering Research and Developments, vol. 39, no. 3, 2016, pp. 607-616.

[8] F. Bouras, M.E.H. Attia and F. Khaldi, Entropy Generation Optimization in Internal Combustion Engine, Environ. Process, vol. 02, 2015, pp. 233-242.

[9] F. Bouras, A. Soudani, and M. Si Ameur, Large Eddy Simulation for Lean Premixed Combustion, Canadian Journal of Chemical Engineering, vol. 91, 2013, pp. 231237.

[10] F. Bouras, A. Soudani, and M. Si Ameur, Numerical Study of the Turbulent Flow Inside an ORACLES Configuration, Trans. ASME, Journal of Appllied Mechnics, vol. 79, 2012, pp. 510-514.

[11] F. Bouras, Numerical study of turbulent structures for lean premixed prevaporized combustion, Journal of Applied Mechanics and Technical Physics, vol. 55, 2014, pp. 614626.

[12] F. Bouras, M.E.H. Attia, F. Khaldi and M. SI-AMEUR. Control of the Methane Flame Behavior by the Hydrogen Fuel Addition: Application to Power Plant Combustion Chamber, International Journal of Hydrogen energy, vol. 42, 2017, pp. 8932- 8939.

[13] M.E.H. Attia, Z. Driss, A. Khechekhouche. Numerical Study of the Combustion of CH4-C3H8/Air: Application to a Combustion Chamber with Two Coaxial Jets, International Journal of Energetica, vol. 2, no. 2, 2017, pp. $38-42$.

[14] M.E.H. Attia, A. Khechekhouche, Z. Driss. Numerical Simulation of Methane-Hydrogen Combustion in the Air: Influence on Combustion Parameters, Indian Journal of Science and Technology, vol. 11, no. 2, 2018, pp. 1-8. 